\title{
Business ethics in developing countries
}

\author{
G.J. Rossouw \\ Department of Philosophy \\ Rand Afrikaans University \\ JOHANNESBURG
}

\begin{abstract}
Underlying this paper is the conviction that it is of the utmost importance that business ethics should indeed become an integral part of business culture in all, and therefore also in developing countrics. It is not to be denied that business ethics has to a much larger extent become part of the business culture in developed countries than in developing countries. The primary aim of this paper is to provide an explanation for the fact that business ethics is fighting an uphill battle in becoming part of the business culture in developing countries. Secondly, a thumbnail sketch is given of the preconditions that have to be fulfilled in order to stimulate the development of a moral business culture in developing countries. In order to achieve these goals I will focus mainly an Africa, and more specifically on South Africa.
\end{abstract}

\section{THE PROBLEM}

During the three decades following the sixties business ethics has become a buzz word in developed countries all over the world. In many instances it has indeed become more than a buzz word - it has become part of the corporate culture of many leading business companies. When one looks at developing countries, however, the situation is somewhat different. In these countries, the concept of business ethics also arises ever more frequently, but it has not by any means succeeded in transforming the business culture to the same extent than it has in developed countries. 1 This discrepancy between developed and developing economies, poses a severe problem for people involved in international business. It means that such people are often confronted with two different sets of moral standards. Especially those persons committed to the moral culture of their companies experience this discrepancy most painfully when their moral commitments become a handicap while dealing with people from countries or societies who do not consider business ethics important.

1 This of course does not mean that there are no examples of moral business culture in developing countries. Some big corporations in developing countries indecd adhere to ethical codes and standards. In comparison to developed count ries, however, the number of such morally committed companies are very few. 
In this article, the primary aim is to provide an explanation for the fact that business ethics is fighting an uphill battle in becoming part of the business culture in developing countries. Secondly, a thumbnail sketch is given of the preconditions that have to be fulfilled in order to stimulate the development of a moral business culture in developing countries. In order to achieve these goals I will focus mainly on Africa, because it is the continent on which I live. More specifically, I will focus on South Africa, because it is my home country and therefore also the part of Africa with which I am best acquainted.

Underlying this paper is the conviction that it is of utmost importance that business ethics should indeed become an integral part of business culture in all countries, and therefore also in developing countries. I hold this conviction for various reasons of which only two are mentioned:

* The one is that immoral conduct in the sphere of business also undermines morality in society at large. Bribery in business deals, for example, does not only have implications for business, but it also undermines the principle of trust which is indispensable for building a secure and good society (cf. DeGeorge, 1986:61).

* The other reason is that business ethics is needed in order to prevent and inhibit capitalism from harming employers, consumers, society and the ecology. I too believe, with Stone, (1989:442-446) that reliance solely on the market principle and the law is insufficient for preventing or dealing with the problems created by capitalism. In this respect I am not opposed to capitalism, but believe that capitalism should be protected against itself.

The problem which business ethics has in becoming an integral part of business culture in developing countries will subsequently be addressed.

\section{EXPLANATION OF THE PROBLEM}

Before tackling the mentioned problem, it is important to define morality. Morality or ethics should be distinguished from values in general. Not all values can be considered as being moral values. It is true that both the person involved in the giving or the taking of bribes, as well as the manager who treats his or her employees and customers in a responsible way, are motivated by certain values. However, there is no way in which the values of the person involved in bribery could be described as moral values. The 
values of the mentioned manager, on the other hand, can be described as being moral. This indicates that only those values that seek the well-being of other people can be considered as moral values. Hoffman and Moore (1990:1) support this conviction when they say: "Ethics is the study of what is good or right for human beings (1990:1). The two key concepts associated with morality are thus the good and the other. Velasquez (1982:12) also confirms this notion of morality when he says:

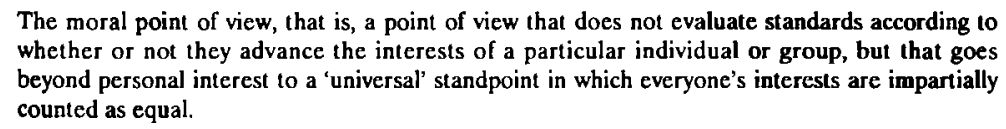

Business ethics is the specific application of this general principle to business activities. To act morally within the business environment therefore means that one should ensure that the consequences of one's business actions contribute not only toward one's own well-being, but also toward the well-being of other persons or societies which are influenced by one's actions.

A broad range of ethical theories have been developed to identify how one should determine what actually is good not only for oneself but also for other persons. These broad range of theories could be divided into two basic approaches to moral decisionmaking, viz the deontological and consequensialistic approaches (cf. Esterhuyse, 1991:17-25; Hoffman \& Moore, 1990:5-18). In this article the issues of moral dissensus and moral relativism produced by this multiplicity of moral theories will not be dealt with. I have addressed these issues as well as moral decision-making amidst moral dissensus in another article (cf. Rossouw, 1992).

In order to provide a possible explanation for the lack of business morality (and indeed the lack of public morality) in developing countries, a theoretical model will be utilized - a model which is on the one hand an oversimplification, but for that very same reason also a handy instrument to get a theoretical grip on the problem. The chosen model is based on the assumption that individuals or a group of individuals (like a business) do not come into the world as fully developed moral agents, but undergo a process of moral development. ${ }^{2}$ In this development process three broad phases can be distinguished. It is, however, not implied that all persons or groups neccessarily have to go through all the phases or even that they do go through these mentioned phases.

2 The model correlates to a certain extent with the theory of moral development which Kohlberg developed for the explanation of individual moral development (cf. Kohlberg 1981). 
Neither is it implied that this moral development will happen spontaneously in an evolutionary way. It might not start at all, or in the case of a person or group of persons who have developed to a higher stage of morality, regression to lower levels might also occur.

The model can graphically be presented as follows in figure 1 .

Figure 1: A proposed model of moral development

\begin{tabular}{|l|l|l|l|}
\hline PHASE & ATTITUDE & STYLE & AIM \\
\hline $\begin{array}{l}\text { Survival } \\
\text { phase }\end{array}$ & $\begin{array}{l}\text { Fear of } \\
\text { extinction }\end{array}$ & Compete & Survival \\
\hline $\begin{array}{l}\text { Reactive } \\
\text { morality }\end{array}$ & $\begin{array}{l}\text { Fear of } \\
\text { rejection }\end{array}$ & Conform & Acceptance \\
\hline $\begin{array}{l}\text { Pro-active } \\
\text { morality }\end{array}$ & Hope & Innovate & $\begin{array}{l}\text { Integrity } \\
\text { meaning }\end{array}$ \\
\hline
\end{tabular}

\subsection{Survival morality}

The first phase of moral development can be described as the phase of survival. In the case of business it refers to that stage when the main aim of a business is to avoid bankruptcy. At that stage there is no indication or warranty that the business will, in the long run, survive and prosper financially. The dominant driving force at that stage therefore, is the fear of financial extinction or death. The typical style of behaviour in this phase is to compete fiercely and uncompromisingly with anyone that is perceived as a threat for survival. In this situation moral considerations are often overridden by the prospect of material gain - people cannot afford losing any income whatsoever. This first phase is strictly speaking a pre-moral phase because the two key concepts associated with morality, viz. the good and the other, are still obviously absent here. The only considerations taken into account at this stage are those that are considered as good for the survival of that specific business.

Some might object that the recognition of a survival phase could easily be misused as an alibi to be permanently engaged in immoral behaviour. This argument could, however, be countered on two grounds. Firstly, it has already been indicated that this phase of survival only applies when there are no realistic prospects for survival on the 
medium or long term. Secondly, I also believe that business people who are serious about their future, will soon realize that the only way to run a business succesfully in the long run, is by gaining the respect and appreciation of the community in which they operate. It goes without saying that very few people will respect, appreciate or support a business that is continuously involved in cheating or other immoral activities.

\subsection{Reactive morality}

This last consideration has already paved the way for the second phase of moral development, which I wish to call the phase of reactionary morality. When the bare minimum requirements for survival have been met, or the prospect of survival in the long run appears, a business can afford to take moral considerations into account What typically happens at this stage is that a business realizes it should respect the wishes and requirements of its social environment, if it wishes to prosper in the long run. A business, like humans, needs acceptance by those surrounding it, in order to prosper and survive. Society demands for example that business should respect the laws of the state, protect the ecology and enhance the quality of life of its employees. The driving force of business in this phase then is the fear of rejection by its social environment. For this reason, business should conform to the demands of society in order to gain acceptance by society.

\subsection{Pro-active morality}

The third and highest form of moral development is the phase of pro-active morality. Instead of only reacting to the demands that society puts to business, it now takes the initiative when it comes to morality. At this stage business sees itself as an integral part of the larger community and makes an explicit choice to act in such a way that its activities will contribute to the creation of a healthier and more humane society (cf. Mellema, 1991:191). The dominant driving force in business now becomes the hope that its activities, products and services will enhance the development of its social and natural environment. In order to do this, business has to innovate, because it is the responsibihity of business itself to determine the extent and nature of its unique contribution to society. It simply has to work it out itself in a way which will match its resources. The result of this moral innovation is that business will experience that it creates more meaning in its society and this in turn will foster a sense of integrity. When this stage arrives it does not mean that survival and acceptance have become 
unimportant. It simply means that these considerations are in harmony with the proactive moral commitment of the business.

When this model is applied to the problem under discussion it seems that the lack of moral awareness in business in developing countries should be attributed to the fact that most businesses are involved in a struggle for survival and can therefore not afford morality. Although this is true in many cases, it is, however, not an adequate reason for the lack of business morality. There surely are a significant number of businesses that cannot be described as being in a survival phase, but nevertheless still act immorally. The explanation for this phenomenon might be twofold.

* On the one hand it might be that people who adhere to immoral practices after they had succeeded in overcoming the phase of survival, simply persist with a style of doing business which stems from the earlier phase.

* On the other hand there might also be certain structural deficiencies in these societies which restrain business from developing to either the reactive or the pro-active moral phase.

These possible causes of the lack of moral awareness in business in developing countries will now be discussed in detail.

\section{CAUSES OF IMMORALITY IN BUSINESS}

\subsection{Bread first, morals later}

The first and most important cause of immoral business conduct in developing countries is the combination of scarcity of consumer goods on the one hand and the enormous competition in obtaining these goods amongst the population on the other hand. This competition often is so fierce that many people's lives are turned into a struggle for survival. When one's survival is at stake, it is only human to satisfy one's own needs before tending to those of others - in other words, it becomes a case of bread first. morals later. Although there are some notable and heroic exceptions to the rule, most moral philosophers do not regard it as irrational to secure one's own survival before entering into altruistic or moral behaviour - on the contrary, in order to be engaged in altruistic behaviour one needs to be alive and well.

This principle, that the concern for your own survival could legitimately override altruistic and moral concerns, is widely accepted amongst respected moral philo- 
sophers. When Peter Singer (1989:38) formulates his two well-known principles, which should guide us in making decisions on aid for the needy, he acknowledges that our attempts to help the needy should never have detrimental effects on our own survival and well-being. This same principle is also generally accepted by anti-abortionists. One of the few cases in which they would justify an abortion, is when the fetus becomes a real threat to the survival of the mother (cf. Callahan, 1989:174). In both above mentioned cases we would generally regard it as either heroism or folly if a person sacrifices his/her own life for either the poor or the unborn. Due concern for one's own survival is thus not per se immoral conduct, but could be justified on rational grounds.

If this is true in the case of aid for the needy and abortion, it should also be true in the case of business. In business, situations may also arise where the survival of the person in business might override other moral concerns. DeGeorge (1986:83-87) refers to such situations as excusing conditions. The following hypothetical example might suffice to proof the point. In Mozambique there is an accute shortage of food and work, because of, amongst other things, the civil war in the country, the mistakes of the pre-independence colonial regime and the economic policy of the first post-independence government. A jobless and therefore hungry father of a hungry and malnutritioned family is offered a job as a worker in the harbour. He has to load and unload the cargo from the ships of the company which hired him. While faithfully performing his job to the best of his ability, he discovers that the cargo of the ships consists of guns, drugs and ivory. He realizes that he is assisting a company which is engaged not only in illegal activities, but is also, through its actions, destroying both human and animal life. If he quits his job he knows that his chances to find alternative employment are pretty poor, because of the extremely high unemployment rate. He therefore either has to continue with the job and the immoral nature thereof, or he has to quit - which would result in starvation - and he would no longer be able to buy medicine for his ailing child. Could this man be blamed if he decides not to quit his job?

That this hypothetical example is not too far removed from the reality in Africa, is illustrated by a recent article published in a South African newspaper. It was found that many jobless people are involved in criminal activities, because there is no other - way to secure an income. In the newspaper article the 'career' of Mandla (not his real name), a St. 8 pupil who was already convicted for house-breaking and theft, and who was out on bail, is described in the following way:

Mandla stays with his mother who works as a domesticworker, his two sisters and a brother who had passed matric and 'is idling because there is no money to send him to university', he said. 
Mandla proudly admitted to stealing because he saw no other way to help his mother buy food and clothe four schoolgoing children. 'Our father passed away in 1986 and my mother struggled to raise us'. ... 'I would like to go to university when I pass matric, but I know she can't afford the fees'. Mandla knows that he might get shot while stealing but he vowed that that won't stop him from doing his 'job'. 'How will I survive if I stopped?' he asked. (Mkhuma, 1991:6.)

The above argument and examples should not be seen as attempts to sanction immoral business behaviour in developing countries. Immoral acts do not become moral acts when they are performed in the difficult conditions of developing countries. The important point, however, is that immoral acts, born out of the struggle for the survival, is understandable. Just as one can never say that it is a good thing in itself when a fetus is aborted because of the danger that it poses to the life of the mother, it too is nevertheless a reasonable and understandable action to take under such circumstances. Immoral acts performed in survival mode are therefore not on par with the same immoral action performed in situations where survival is no longer the prime concern. It is extremely important that business people from developed countries should bear this in mind when they are conducting business in developing countries. It is unfair to measure the conduct of people in situations of survival by the standard of behaviour that one might expect from people in developed countries whose most basic needs are fulfilled.

\subsection{Bad habits}

Not all immoral business conduct in developing countries could be ascribed to the struggle for survival. There certainly is a substantial number of business people who have moved beyond the struggle for survival, but who nevertheless still persist in acting immorally in their business activities. In a recent Gallup Poll conducted by a well known South African research company, business executives achieved a 37\% honesty rating, while insurance salesmen, estate agents and motorcar dealers fared even worse. These findings are also supported by research done by Dr. Nicholls in which he established that executives in 59 top South African companies "rate honesty as relatively unimportant" (Fothergill, 1990:4). This type of immoral conduct which one finds among the more affluent business people in developing countries, is neither understandable, nor excusable. There are two explanations for this kind of immoral conduct. The one will be dealt with in the next section. The other is that such people have extended behaviour which was meant for survival, to a situation in which survival is no longer the prime concern. 
The motivation given by such people for their behaviour is a typical $t u$ quoque or 'you too' argument (cf. Van Veuren, 1991:92). The gist of this argument is that if some people act immorally, there is no reason why others must act morally in their business dealings. They argue that it is unfair to expect them to behave morally, when their opponents do not adhere to the same moral demands. They therefore often use a type of war morality in which they claim that one's basic consideration is whether one wants to be involved in business or not (cf. D'Andrade, 1990:95-103). Once one has made that decision, one simply has to accept that it is a case of dog eats dog and play the game accordingly. This type of argument creates a vicious circle and thus perpetuates and even encourages more aggressive immoral behaviour. In the concluding section, a few remarks about breaking this vicious circle will be made.

\subsection{Structural deficiencies in society}

The third cause of the immorality that prevails in the business sector in developing countries, is the lack of social control over the business community by the larger society in which business operates. In the model presented in the first part of this paper, it was indicated that reactive morality is the first stage of moral development in the context of business. Reactive morality thus is a response to the demands of society that business should not harm the well-being of society. It is clear that in order to provoke at least this kind of reactive morality amongst people involved in business, an organized and informed community which are aware of its democratic rights are required. These three requirements are, to a certain extent, lacking in Africa. The organized community life in Africa has very often been disturbed, if not totally uprooted by colonial regimes and in the case of South Africa also by the apartheid regime. The political turmoil that has plagued Africa ever since the demise of the colonial era, could partly be attributed to the struggle to find a new and viable postcolonialist community structure. Africa is furthermore characterised by illiteracy and therefore also by a low standard of education. A substantial part of the population is poorly informed about politics, economics and the sociological interaction in society. It is exactly this kind of information and knowledge that is required to make a social analysis of one's society. People who do not understand the social workings of their society, can not change and influence their society. The development of at least reactive morality is thus severely retarded by the lack of social knowledge in most developing countries. The same holds true when it comes to democratic values. Although it would be a crude generalization to say that people in developing countries and specifically in Africa do not have a good understanding nor experience of democracy, ${ }^{3}$ it could on the other hand also not be

3 In their book Suid-Afrika: die oplossing, Leon Louw and Francis Kendall (1986:4-7) convincingly argue that a kind of democracy had been practised by the tribal leaders at the 
denied that Africa's record of democracy is rather poor. One party states, dictatorships and military rule are very common in Africa. The United Nations also has repeatedly indicated that human rights abuses are very common in Africa. The underdevelopment or even lack of democratic procedures makes it extremely difficult for workers and consumers to respond effectively when business people treat them immorally. This list of structural deficiencies which hampers the development of at least reactive morality amongst the business community in developing countries, pretends by no means to be complete. Other factors like insufficient mass communication could still be added to the list.

The above mentioned factors that restricts the development of reactive morality, also have a negative impact on the development of pro-active morality. It is undeniably true that the moral genius could turn his or her back on the immorality in the business sector and decide to take an alternative approach where she or he doesn't partake in immoral business activities. ${ }^{4}$ Without these mentioned conditions for reactive business morality being fulfilled, they could choose to act in a moral way and to contribute through their business activities towards the development of a better and more meaningful society. Although such a leap is possible, it is nevertheless much easier to make this sort of choice once one has been introduced to morality through reactive morality. It could therefore be expected that much more people will opt for pro-active morality once the basis of reactive morality has been established, because even the genius and the innovator are stimulated by positive developments in their societies.

\section{WHAT SHOULD BE DONE?}

In concluding this paper, a thumbnail sketch is given of the conditions to be met in order to improve business morality in developing countries. It should be clear by now that just a simple appeal by people in developed countries to the business people in developing countries would serve no purpose. The causes of immorality are not merely to be blamed on a wrong disposition on the side of people involved in business in

time when the colonial invasion of Africa took place. This form of democracy, however, was in many cases destroyed by the political order which the colonial regimes in Africa forced onto these communities.

4 See Hick's treatment of the socially detaching power of conscience that enables a person to transcend the limitations of the traditon and the community in which he or she lives (Hick, 1990:32). 
developing countries. The immorality caused by the struggle for survival of people involved in business, could only be solved when the basic requirements for survival are fulfilled. This means that the fierce competition for the limited resources and goods needed for survival should be reduced. A reduction of this competition could only be achieved by the increase of the goods and resources needed or by reducing the number of people that are fighting for mere survival. In order to achieve the former, a rise in productivity, job creation, foreign investment and other similar actions are needed. In order to achieve a decrease in the number of people competing for the scant resources and goods, a combination of upward economic mobility and population control is needed.

When it comes to the development of reactive morality, an organized, informed and democratic society is needed. This means that political development that will secure justice and the protection of human rights and the enhancement of a stable community life should occur. Education should not only be improved, but also adapted in order to prepare students for participation as responsible and caring members in their communities.

For the development of pro-active morality, at least the above mentioned requirements should be met. It could, however, be further stimulated by the promotion of the idea of pro-active morality among business people, as well as by the circulation of case examples of successful business people who are motivated and driven by pro-active moral concerns.

The one thing that obviously is lacking from the above proposals, is the agent or agents who should take the responsibility for managing these changes in society. It seems that every person or institution or company that is negatively affected by the lack of business morality in developing countries, qualifies as an agent for this process of change. That includes inter alia governments, multinational corporations, business people involved in trade with developing countries, consumers, community organizations and churches.

\section{BIBLIOGRAPHY}

CALLAHAN, D. 1989. Abortion: Law, Choice and Morality. (In Olen, J. \& Barry, V. Applying Ethics. Belmont : Wadsworth. p. 171-176.)

D'ANDRADE, K. 1990. Foundations of Business Ethics. Michigan : UMI.

DEGEORGE, R.T. 1986. Business Ethics (2nd ed). New York: Macmillan.

ESTERHUYSE, W.P. 1991. Sake-ctiek in die praktyk. Pretoria : J.L. van Schaik. 
FOTHERGILL, M. 1990. Honesty in Business? What's That? Sunday Star :4. Jul. 7.

HICK, J. 1990. Philosophy of Religion (4th ed.). Englewood Cliffs : Prentice-Hall.

HOFFMAN, W.M. \& MOORE, J.M. 1990. Business Ethics. New York : McGraw-Hill.

KOHLBERG, L. 1981. The Philosophy of Moral Development. San Francisco : Harper and Row.

LOUW, L. \& Kendal, F. 1986. Suid Afrika: die oplossing. Bisho : Amagi Publishers.

MELLEMA, G. 1991. Supererogation and Business Ethics. Joumal of Applied Philosophy, 8(2):191-199.

MKHUMA, Z. 1991. We Stole Just to Survive, Say Three Youths. The Star :6. Nov. 11.

ROSSOUW, G.J. 1992. Rational Interaction for Moral Sensitivity: A Postmodern Approach to Moral Decision-Making in Business (unpublished paper).

SINGER, P. 1989. Famine, Affuence and Morality. (In Olen J. \& Barry, V. Applying Ethics. Belmont : Wadsworth. p. 346-356.)

STONE, C.D. 1989. The Corporate Social Responsibility Debate. (In Olen, J. \& Barry, V. Applying Ethics. Belmont : Wadsworth. p. 438-446.)

VAN VEUREN, P. 1991. Argumente, kriteria, kritick. Pretoria : RGN.

VELASOUEZ, M.G. 1982. Business Ethics. New York: Prentice Hall 